\title{
Barley $\beta$-glucan reduces blood cholesterol levels via interrupting bile acid metabolism
}

\author{
Yanan Wang ${ }^{1,2,3}$, Scott V. Harding ${ }^{1,4}$, Sijo J. Thandapilly ${ }^{1,2,3}$, Susan M. Tosh ${ }^{5}$, Peter J. H. Jones ${ }^{2,3}$ and \\ Nancy P. Ames ${ }^{1,2,3 *}$ \\ ${ }^{1}$ Morden Research and Development Centre, Morden, Manitoba, R6M 1Y5, Canada \\ ${ }^{2}$ Human Nutritional Sciences, University of Manitoba, Winnipeg, Manitoba, R3T 2N2, Canada \\ ${ }^{3}$ Richardson Centre for Functional Foods and Nutraceuticals, Winnipeg, Manitoba, R3T 2N2, Canada \\ ${ }^{4}$ Diabetes and Nutritional Sciences, King's College London, London SE1 9NH, UK \\ ${ }^{5}$ Guelph Research and Development Centre, Agriculture E Agri-Food Canada, Guelph, Ontario, N1G 5C9, Canada \\ (Submitted 7 February 2017 - Final revision received 25 August 2017 - Accepted 6 September 2017-First published online 8 November 2017)
}

\section{Abstract}

Underlying mechanisms responsible for the cholesterol-lowering effect of $\beta$-glucan have been proposed, yet have not been fully demonstrated. The primary aim of this study was to determine whether the consumption of barley $\beta$-glucan lowers cholesterol by affecting the cholesterol absorption, cholesterol synthesis or bile acid synthesis. In addition, this study was aimed to assess whether the underlying mechanisms are related to cholesterol $7 \alpha$ hydroxylase (CYP7A1) SNP rs3808607 as proposed by us earlier. In a controlled, randomised, crossover study, participants with mild hypercholesterolaemia ( $n$ 30) were randomly assigned to receive breakfast containing $3 \mathrm{~g}$ high-molecular weight (HMW), $5 \mathrm{~g}$ low-molecular weight (LMW), $3 \mathrm{~g}$ LMW barley $\beta$-glucan or a control diet, each for 5 weeks. Cholesterol absorption was determined by assessing the enrichment of circulating ${ }^{13} \mathrm{C}$-cholesterol over $96 \mathrm{~h}$ following oral administration; fractional rate of synthesis for cholesterol was assessed by measuring the incorporation rate of ${ }^{2} \mathrm{H}$ derived from deuterium oxide within the body water pool into the erythrocyte cholesterol pool over $24 \mathrm{~h}$; bile acid synthesis was determined by measuring serum $7 \alpha$-hydroxy-4-cholesten-3-one concentrations. Consumption of 3 g HMW $\beta$-glucan decreased total cholesterol (TC) levels $(P=0 \cdot 029)$, but did not affect cholesterol absorption $(P=0 \cdot 25)$ or cholesterol synthesis $(P=0 \cdot 14)$. Increased bile acid synthesis after consumption of $3 \mathrm{~g}$ HMW $\beta$-glucan was observed in all participants $(P=0.049)$, and more pronounced in individuals carrying homozygous $\mathrm{G}$ of rs3808607 $(P=0.033)$. In addition, a linear relationship between $\log$ (viscosity) of $\beta$-glucan and serum $7 \alpha$-HC concentration was observed in homozygous $\mathrm{G}$ allele carriers. Results indicate that increased bile acid synthesis rather than inhibition of cholesterol absorption or synthesis may be responsible for the cholesterol-lowering effect of barley $\beta$-glucan. The pronounced TC reduction in G allele carriers of rs 3808607 observed in the previous study may be due to enhanced bile acid synthesis in response to high-viscosity $\beta$-glucan consumption in those individuals.

\section{Key words: $\beta$-Glucan: CYP7A1: Molecular weight: Viscosity: Cholesterol: Bile acids: Mechanisms}

Previous studies have demonstrated the critical roles of the high viscosity and molecular weight (MW) of $\beta$-glucan in its cholesterol-lowering effect ${ }^{(1,2)}$. Yet, to date the precise underlying mechanisms responsible for the action of $\beta$-glucan reducing blood cholesterol have not been well elucidated.

Cholesterol in humans is mainly determined by cholesterol de novo synthesis, dietary cholesterol intake and conversion to bile $\operatorname{acid}^{(3)}$. It has been proposed that $\beta$-glucan may reduce cholesterol via impacting any three of these pathways. $\beta$-Glucan is not absorbed by the small intestine, however, the physicochemical properties of $\beta$-glucan may alter the luminal environment and lead to increased transit time and thickness of the unstirred water layer (UWL), consequently reducing cholesterol absorption $^{(4)}$. When $\beta$-glucan enters the large intestine, gut microbiota present in the colon are responsible for its degradation $^{(5,6)}$. By-products resulting from $\beta$-glucan fermentation, SCFA, might then affect cholesterol synthesis ${ }^{(7-9)}$. In addition, cholesterol is the substrate for bile acid synthesis in the liver, thus $\beta$-glucan may affect cholesterol metabolism via interfering bile acid enterohepatic circulation. Approximately $95 \%$ of the bile acids are reabsorbed in the terminal ileum ${ }^{(10,11)}$ while a small amount of bile acids are excreted with the faeces ${ }^{(10)}$. The conversion of bile acid from cholesterol occurs at a rate that precisely corresponds to the loss of bile acids within the faeces $^{(12)}$. $\beta$-Glucan has been thought to work as a bile acid sequestrant reducing cholesterol by decreasing bile acid

Abbreviations: $7 \alpha$-HC, $7 \alpha$-hydroxy-4-cholesten-3-one; CYP7A1, cholesterol $7 \alpha$ hydroxylase; FRS, fractional rate of synthesis; HMW, high-molecular weight; LWM, low-molecular weight; MW, molecular weight; TC, total cholesterol.

*Corresponding author: N. P. Ames, fax +1 204474 7552, email nancy.ames@agr.gc.ca 
reabsorption and further up-regulating bile acid synthesis and thus consuming more cholesterol ${ }^{(13,14)}$. The interruption of bile acid enterohepatic circulation resulting from $\beta$-glucan consumption has been observed in ileostomy patients ${ }^{(15)}$, yet, evidence from healthy participants in supporting this proposed mechanism is limited.

Cholesterol 7- $\alpha$ hydroxylase (CYP7A1) is the rate-limiting enzyme in the classical bile acid synthetic pathway in humans ${ }^{(16)}$. Its activity can be indicated by the circulating concentration of $7 \alpha$-hydroxy-4-cholesten-3-one ( $7 \alpha-\mathrm{HC})$, a bile acid intermediate of the classical synthesis pathway ${ }^{(16,17)}$. Genetic variation of CYP7A1 SNP rs3808607 has been associated with different responses to high-viscosity $\beta$-glucan in lowering cholesterol levels in our previous study, where G allele carriers of CYP7A1 SNP rs3808607 showed more pronounced responses in reducing total cholesterol (TC) than $\mathrm{T} / \mathrm{T}$ allele carriers ${ }^{(2)}$. The biological difference between $\mathrm{G}$ and $\mathrm{T}$ alleles in regulating bile acids and cholesterol metabolism is not entirely clear. Results from De Castro-Oros et al.'s ${ }^{(18)}$ study suggested that the $T>G$ polymorphism might regulate cholesterol catabolism differently due to their varied ability in modulating transcriptional activity of $C Y P 7 A$ gene. $G$ allele was speculated to be more responsive to dietary intervention in elevating the bile acid synthesis ${ }^{(18)}$. However, evidence from different phenotypes, in terms of bile acid synthesis at physiological level, is needed to confirm this speculation.

Collectively, our hypotheses are: (1) $\beta$-glucan lowers blood cholesterol levels via suppressing cholesterol absorption, decreasing cholesterol biosynthesis and /or interrupting the enterohepatic circulation of bile acids; and (2) G allele carriers of rs3808607 have a higher level of bile acid synthesis in response to $\beta$-glucan intervention. Accordingly, the primary objective of this study was to assess whether lowered serum cholesterol levels resulting from $\beta$-glucan consumption are due to inhibition of cholesterol absorption, cholesterol synthesis or increased bile acid synthesis. The additional objective was to assess the phenotype of $C Y P 7 A 1$ SNP rs3808607 in response to $\beta$-glucan intervention at a physiological level.

\section{Methods}

\section{Diet and clinical trial procedure}

A randomised, single-blinded, diet-controlled, cross-over trial was conducted at the Clinical Nutrition Research Unit at the Richardson Centre for Functional Foods and Nutraceuticals (RCFFN), University of Manitoba, Winnipeg. Participants with serum cholesterol between 5.0 and $8.0 \mathrm{mmol} / \mathrm{l}$, LDL-cholesterol between 2.7 and $5.0 \mathrm{mmol} / \mathrm{l}$ ( $n$ 30) were randomly assigned to receive barley diets containing $3 \mathrm{~g}$ high MW (HMW, $13.5 \times 10^{5} \mathrm{~g} / \mathrm{mol}$ ), $5 \mathrm{~g}$ low MW (LMW, $\left.2.9 \times 10^{5} \mathrm{~g} / \mathrm{mol}\right), 3 \mathrm{~g} \mathrm{LMW}\left(2.9 \times 10^{5} \mathrm{~g} / \mathrm{mol}\right) \beta$-glucan or a control diet, each for 5 weeks. The washout period between the study phases was $\geq 4$ weeks. Breakfast foods in the format of crepes, tortillas, porridge and chips were formulated from barley to contain $\beta$-glucan varying in MW and dose or formulated from wheat and rice to substitute barley ingredients as a control. Lunch and dinner were provided to meet the energy needs of each subject. Overall, participants received study diets containing
Table 1. Nutrient content of the experimental diets

\begin{tabular}{lcrrr}
\hline & WR control & 3g LMW & 5g LMW & 3g HMW \\
\hline Energy (kJ/d) & 11803 & 11895 & 11937 & 11895 \\
Energy (kcal/d) & 2821 & 2843 & 2853 & 2843 \\
Carbohydrate (\% energy) & 55.7 & 55.7 & 55.6 & 55.7 \\
Fibre (g/d) & 31.2 & 36.6 & 41.5 & 36.6 \\
$\quad$ Soluble fibre (g/d) & 5.7 & 8.7 & 10.7 & 8.7 \\
$\beta$-Glucan (g/d) & $<0.24$ & 3.0 & 5.0 & 3.0 \\
Protein (\% energy) & 15.9 & 15.9 & 15.9 & 15.9 \\
Fat (\% energy) & 30.8 & 30.5 & 30.4 & 30.5 \\
$\quad$ Saturated (\% energy) & 9.0 & 8.9 & 8.9 & 8.9 \\
Cholesterol (mg/d) & 312.7 & 312.7 & 312.7 & 312.7 \\
\hline
\end{tabular}

WR, wheat and rice; LMW, low-molecular weight; HMW, high-molecular weight; fibre, total dietary fibre.

approximately $30 \%$ of energy as fat, $55 \%$ as carbohydrate and $15 \%$ as protein but with different levels of soluble fibre. Details of nutrition information for the study diets have been reported in a previous paper ${ }^{(2)}$ and are shown in Table 1. Participants consumed breakfast at the Clinical Nutrition Research Unit of RCFFN from Monday to Friday. Lunch and dinner for weekdays were picked up by participants and consumed at home. Weekend meals including breakfast were delivered to participant' home address. This study was conducted according to the principles expressed in the Declaration of Helsinki and all research procedures were approved by the University of Manitoba's Biomedical Research Ethics Board (Ethic reference no. B2010:057).

\section{Serum lipid and genotype determination}

Methods for determining blood lipid concentrations and the genotype of CYP7A1 SNP rs3808607 have been described in the previous study ${ }^{(2)}$. In brief, $12 \mathrm{~h}$ fasted blood samples were collected on days 1, 2, 34 and 35. Blood samples were centrifuged at $2675 \mathrm{~g}$ for $20 \mathrm{~min}$ at $4^{\circ} \mathrm{C}$, separated into serum, plasma, buffy coat and erythrocytes, and stored at $-80^{\circ} \mathrm{C}$ until analysis. An average of values of days 34 and 35 were used for endpoint analysis for blood lipids. Serum TC, HDL-cholesterol and TAG were measured using the automated enzymatic methods on a Vitros-350 chemistry analyzer (Ortho Clinical Diagnostics). Serum LDLcholesterol was estimated using the Friedewald equation ${ }^{(19)}$. DNA used for SNP determination were extracted from the buffy coat of heparinised blood samples following the instructions of the Dneasy ${ }^{\circledR}$ Blood \& Tissue kit (QIAGEN). SNPs of rs3808607 for CYP7A1 were genotyped using TaqMan ${ }^{\circledR}$ GTXpress ${ }^{\text {TM }}$ Master Mix (Applied Biosystems, Inc.) with allele-specific probes on the StepOnePlus ${ }^{\text {TM }}$ Real-Time PCR System (Applied Biosystems, Inc.).

\section{Cholesterol absorption}

The cholesterol absorption in response to $\beta$-glucan intervention was determined by stable isotope $\operatorname{method}^{(20,21)}$. On day 30 of each study phase, participants ingested approximately $5 \mathrm{~g}$ of margarine with $75 \mathrm{mg}$ of $\left[3,4-{ }^{13} \mathrm{C}\right]$ cholesterol $(99 \%$ atom percentage excess; Cambridge Isotope Laboratories) spread on half of an English muffin. Fasted blood samples were obtained before oral administration of isotope tracers $(0 \mathrm{~h})$ and also in the following $96 \mathrm{~h}$ on day 31 ( $24 \mathrm{~h}$ ), day 32 ( $48 \mathrm{~h})$, day 33 ( $72 \mathrm{~h})$, and day 34 (96h). Free cholesterol was extracted from 
erythrocytes by modified Folch procedure ${ }^{(22)}$. The isotopic enrichment of $\left[3,4-{ }^{13} \mathrm{C}\right]$ cholesterol was determined using $\mathrm{GC}$ isotope ratio MS (GC-IRMS; Thermo Finnigan) where samples were run through a GC unit, a combustion reactor and a mass spectrometer $^{(20,21)}$. The cholesterol extracts were combusted to ${ }^{13} \mathrm{C}$-enriched $\mathrm{CO}_{2}$ and the combusted $\mathrm{CO}_{2}$ gas was analysed for ${ }^{13} \mathrm{C}$ enrichment against the international standard Vienna Pee Dee Belemnite limestone. The AUC of ${ }^{13} \mathrm{C}$ enrichment from 0 to $96 \mathrm{~h}$ was calculated for determining cholesterol absorption.

\section{Determination of cholesterol biosynthesis}

The fractional cholesterol synthesis rate in response to the intervention diets was determined by stable isotope method using deuterated water ${ }^{(23)}$. Specifically, cholesterol synthesis was assessed by measuring the rate of ${ }^{2} \mathrm{H}$ derived from deuterium oxide $\left(\mathrm{D}_{2} \mathrm{O}\right)$ within the body water pool into the erythrocyte cholesterol pool $^{(23)}$. On day 34 of each study phase, participants ingested $0.7 \mathrm{~g}$ of $\mathrm{D}_{2} \mathrm{O} / \mathrm{kg}$ estimated body water $(60 \%$ of body weight). Fasting blood samples were collected before $\mathrm{D}_{2} \mathrm{O}$ oral administration on day $34(0 \mathrm{~h})$ and day 35 after $\mathrm{D}_{2} \mathrm{O}$ ingestion $(24 \mathrm{~h})$. Blood samples were centrifuged and separated into plasma, buffy coat and erythrocytes, and stored at $-80^{\circ} \mathrm{C}$ until analysis. Total lipids were extracted from erythrocytes by a modified Folch procedure ${ }^{(22)}$. The lipid extracts were separated using GC and isolated cholesterol was submitted into a pyrolysis reactor to release $\mathrm{H}_{2}$ gas. Plasma water samples were run through a high temperature conversion elemental analyser. ${ }^{2} \mathrm{H}$ enrichments for both erythrocytes and plasma water were measured by IRMS relative to the reference gas. Normalisation to Vienna standard mean ocean water was performed using a regression equation between the online and offline method with data from the offline method expressed relative to Vienna standard mean ocean water (V-SMOW). The fractional rate of synthesis (FSR) for cholesterol was calculated using the following equation:

$$
\text { FSR }(\text { pools } / \mathrm{d})=\frac{\Delta \mathrm{D}-\text { cholesterol }}{\Delta \mathrm{D}-\mathrm{PW} \times 0 \cdot 478} \times 100 \% \text {, }
$$

where $\Delta \mathrm{D}$-Cholesterol is the difference in ${ }^{2} \mathrm{H}$ enrichment between 0 and $24 \mathrm{~h}$ for cholesterol; $\Delta \mathrm{D}-\mathrm{PW}$ the difference in ${ }^{2} \mathrm{H}$ enrichment between $0 \mathrm{~h}$ and $24 \mathrm{~h}$ for plasma water; and 0.478 the ratio of labelled $\mathrm{H}$ atoms replaced by ${ }^{2} \mathrm{H}$ during in vivo biosynthesis ${ }^{(20)}$.

\section{Determination of bile acid biosynthesis}

Blood samples for determining bile acid biosynthesis were collected on days 34 and 35 . The mean of $7 \alpha$-HC levels on days 34 and 35 was used for indicating bile acid synthesis level. Bile acid biosynthesis was determined by measuring the serum concentration of $7 \alpha$-HC using the Ultra-Performance Liquid Chromatography (ACQUITY UPLC System; Waters) coupled with a tandem mass spectrometer (Quattro micro ${ }^{\mathrm{TM}}$ API; Waters). $7 \alpha$-HC was extracted by C18-E solid phase extraction (SPE) (Phenomenex ${ }^{\circledR}$ ) mounted on a pump (KNF lab pump; KNF Neuberger) connected SPE processor (Agilent Technologies) following the method modified from Burkard et al. ${ }^{(24)}$. $7 \alpha$-hydroxy-4-cholesten-3-one-d $\mathrm{d}_{7}$ (Medical Isotopes. Inc.) was used as an internal standard. In brief, SPE cartridges were pre-conditioned by $2 \times 2 \mathrm{ml}$ methanol, $2 \times 2 \mathrm{ml}$ water and $2 \times 2 \mathrm{ml} 100 \mathrm{~mm}$ ammonium carbonate buffer $\mathrm{pH} 9 \cdot 3$. Serum $(750 \mu \mathrm{l})$ mixed with ammonium carbonate buffer $(1: 1 \mathrm{v}: \mathrm{v})$ and $150 \mu \mathrm{l}$ of internal standard $(40 \mathrm{ng} / \mathrm{ml})$ were applied to the activated SPE cartridge. Under a vacuum, the speed of the mixture passing the cartridge was controlled within $1 \mathrm{drop} / \mathrm{s}$ passing through the cartridge. Subsequently, the cartridges were washed with $2 \times 2 \mathrm{ml}$ of water and dried under $\mathrm{N}_{2}$. Bile acids were desorbed with $3 \mathrm{ml}$ of methanol with the speed of 1 drop/s for passing the cartridge. The eluted substances were dried under $\mathrm{N}_{2}$ and dissolved in $150 \mu$ l of methanol before injecting into the UPLC. A reserved phase C18 column (Kinetex $^{\mathrm{TM}} 1.7 \mu \mathrm{m}$ XB-C18 $100 \AA$, LC Column $100 \times 2.1 \mathrm{~mm}$; Phenomenex ${ }^{\circledR}$ ) with mobile phase water with $0.1 \%$ formic acid (A) and methanol (B) was used for the separation. The ions used for the tracing of unlabelled $7 \alpha$-HC were $m / z 401>177$ and the ions for tracing the $7 \alpha$-hydroxy-4-cholesten-3-one- $\mathrm{d}_{7}$ were $407>177$. The mass spectrometer was operated in the positive mode. Corona current was $3 \mu \mathrm{A}$, cone voltage $25 \mathrm{~V}$, source temperature $120^{\circ} \mathrm{C}$, cone gas flow 62 litres/h, desolvation gas flow 400 litres/h, and collision energy $23 \mathrm{eV}$. The quantitation was performed with use of a standard curve, plotting the ratio between the response of $7 \alpha$-HC in the $m / z 177$ tracing generated from the mother ion $m / z 401$ (unlabelled) and the response in the $m / z 177$ tracing generated from the mother ion $m / z 407$ (labelled).

\section{Statistical analyses}

Cholesterol absorption indicated by AUC of ${ }^{13} \mathrm{C}$ enrichment, cholesterol synthesis indicated by FSR and bile acid synthesis indicated by serum concentration of $7 \alpha$-HC were analysed using linear mixed-models (PROC MIXED, version 9.2; SAS Institute Inc.). Log transformations were used for data that were not normally distributed ( $7 \alpha$-HC concentrations). For detecting the diet and genotype effects, diet, genotype and genotype $x$ diet were modelled as fixed factors and participants were modelled as the random factor in the mixed-model. Correlation between repeated measures of these individuals was modelled using the first-order autoregressive (AR (1)) option in the PROC MIXED procedure. Fisher's least significant difference tests were used for multiple comparisons. In the genotype sub-group analysis, each genotype group was analysed independently with diet as a fixed factor. Statistical analyses for blood lipids were described in the previous study ${ }^{(2)}$.

Linear regression of $7 \alpha$-HC concentration on $\log$ (viscosity) was performed using SAS (PROCREG, version 9.2; SAS Institute Inc.) and plotted with GraphPad Prism (GraphPad Prism version 6.00 for Windows; GraphPad Software). The nonparametric correlation was performed by using Spearman's rank correlation (JMP ${ }^{\circledR}$, version 10; SAS Institute Inc.). A value of $P<0.05$ was considered to be significant.

\section{Results}

\section{Drop-out rate and genotype distribution}

In all, forty-five participants were recruited for the study. Eight participants dropped out from the study with reasons unrelated 
to the study; seven participants were excluded from the study for reasons including low tolerance to the study diet, missing the study diet, later discovery of ineligibility (e.g. met inclusion criteria at screening but did not meet criteria when day 1 blood samples were analysed). A participant flow chart and baseline characteristics of participants were described in the previous published study ${ }^{(2)}$. In the thirty participants who completed four phases of the study, eleven were identified to be TT allele carriers, eleven

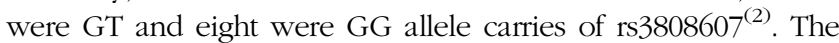
distribution of genoptype of CYP7A1 SNP rs3808607 among the participants in this study is similar to the minor genotype frequency reported in the general population ${ }^{(25)}$.

\section{Changes in serum cholesterol levels and body weight}

Changes in blood lipid levels have been reported in the previous study ${ }^{(2)}$. For the convenience of the readers, these data are included in Table 2 . Consumption of $3 \mathrm{~g} \mathrm{HMW} / \mathrm{d} \beta$-glucan for 5 weeks lowered TC compared with the control $(P=0 \cdot 029)$ but the LMW $\beta$-glucan, at either 3 or $5 \mathrm{~g} / \mathrm{d}$, did not change serum cholesterol concentrations (Table 2). In addition, significant genotype-by-diet effect was observed in changing serum TC and LDL-cholesterol levels for $3 \mathrm{gHMW} \beta$-glucan (Table 2). Consumption of $\beta$-glucan did not change serum HDLcholesterol or TAG levels (Table 2). Changes in body weight and waist circumference were not statistically different among treatments (data not shown).

When the participants were sub-grouped based on their genotypes of CYP7A1 SNP rs3808607, consumption of $3 \mathrm{~g} / \mathrm{d}$ HMW $\beta$-glucan resulted in lower TC levels in $\mathrm{G}$ allele carriers $(\mathrm{G} / \mathrm{T}$ and $\mathrm{G} / \mathrm{G}$ ) and lower LDL-cholesterol in homozygous $\mathrm{G}$ allele carriers $(\mathrm{G} / \mathrm{G})$ (Table 3 ). T/T carriers did not respond to $\beta$-glucan in reducing serum TC or LDL-cholesterol levels. Serum HDL-cholesterol and TAG levels remained unchanged in all genotype groups.

\section{Changes in cholesterol absorption, cholesterol synthesis} and serum $7 \alpha$-hydroxy-4-cholesten-3-one

Cholesterol absorption was not affected by $\beta$-glucan consumption $(P=0 \cdot 25)$. The AUC of $96 \mathrm{~h}$ enrichment of ${ }^{13} \mathrm{C}$ were $539 \cdot 75,542 \cdot 08,546.41$ and 588.38 for the control, $3 \mathrm{~g}$ LMW,
$5 \mathrm{~g}$ LMW and 3 g HMW $\beta$-glucan, respectively (Table 2 ). The FSR for cholesterol was also not affected by $\beta$-glucan ingestion $(P=0 \cdot 14)$. FSR resulting from the experimental diets assessed in a 24-h time window were 8.37, 9.25, 7.54 and 7.80 for control, $3 \mathrm{~g}$ LMW, $5 \mathrm{gLMW}$ and $3 \mathrm{~g}$ HMW $\beta$-glucan, respectively (Table 2). Consumption of $3 \mathrm{~g}$ HMW $\beta$-glucan resulted in higher $7 \alpha$-HC levels compared with control $(14.00$ v. $11.05 \mathrm{ng} / \mathrm{ml}, P=0.049$, Table 2). The $7 \alpha$-HC levels were not affected by LMW $\beta$-glucan, which is consistent with the results of cholesterol changes (Table 2).

In the sub-group analysis, cholesterol absorption and FSR for cholesterol remained unchanged for all genotypes of CYP7A1 SNP rs3808607. Although genotype $\times$ diet effect was not statistically significant for $7 \alpha$-HC concentrations (Table 2 ), the three genotypes of $C Y P 7 A 1$ showed inconsistent results of $7 \alpha-\mathrm{HC}$ concentrations (Table 3). G/G group responded to $3 \mathrm{~g} / \mathrm{d}$ HMW $\beta$-glucan in increasing $7 \alpha$-HC concentrations compared with control $(P=0.033)$; yet serum $7 \alpha$-HC levels were not affected by $\beta$-glucan consumption in $\mathrm{G} / \mathrm{T}$ and $\mathrm{T} / \mathrm{T}$ groups. This observation is consistent with the changes in circulating cholesterol levels that individuals carrying homozygous $G$ allels responded to $3 \mathrm{~g}$ HMW $\beta$-glucan in reducing TC and LDL-cholesterol (Table 3).

\section{Linear relationship between serum $7 \alpha$-hydroxy-4- cholesten-3-one concentrations and viscosity of $\beta$-glucan}

Viscosity of $\beta$-glucan is believed to be the determinant for its cholesterol-lowering effect. Our previous study has shown a linear relationship between viscosity of $\beta$-glucan and cholesterol changes in participants that responded to $\beta$-glucan in reducing their circulating cholesterol levels ${ }^{(2)}$. In this study, results consistently support the critical role of viscosity of $\beta$-glucan in mediating cholesterol metabolism. A linear relationship between viscosity of $\beta$-glucan and $7 \alpha$-HC concentrations was observed in homozygous $\mathrm{G}$ allele carriers $\left(P=0.025, r^{2}\right.$ 0.95, Fig. 1).

\section{Correlation between cholesterol and bile acid kinetic parameters}

In the non-parametric correlation (Table 4), AUC and FSR were negatively related with each other, although the correlation

Table 2. Changes in serum lipids, ${ }^{13} \mathrm{C}$-labelled cholesterol enrichment in erythrocytes, fractional synthesis rate (FSR) for cholesterol and serum $7 a$-hydroxy-4cholesten-3-one (7a-HC) in response to $\beta$-glucan intervention for 5 weeks in mildly hypercholesterolemic adults

(Least squares means (LSM) with their standard errors)

\begin{tabular}{|c|c|c|c|c|c|c|c|c|}
\hline & \multicolumn{4}{|c|}{ Diet } & \multirow[b]{2}{*}{ SEM } & \multicolumn{3}{|c|}{$P$} \\
\hline & WR control & $3 \mathrm{~g} \mathrm{LMW}$ & $5 \mathrm{~g} \mathrm{LMW}$ & $3 \mathrm{~g} \mathrm{HMW}$ & & Diet & Genotype & Genotype $\times$ diet \\
\hline \multicolumn{9}{|l|}{ Changes in blood lipids } \\
\hline Total cholesterol $(\mathrm{mmol} / \mathrm{l})$ & $5 \cdot 49^{\mathrm{a}}$ & $5 \cdot 44^{a, b}$ & $5 \cdot 54^{\mathrm{a}}$ & $5 \cdot 37^{\mathrm{b}}$ & 0.096 & 0.029 & 0.9 & 0.013 \\
\hline LDL-cholesterol ( $\mathrm{mmol} / \mathrm{l})$ & 3.40 & 3.39 & 3.46 & 3.31 & 0.078 & 0.077 & 0.93 & 0.045 \\
\hline HDL-cholesterol (mmol/l) & 1.36 & 1.31 & 1.33 & 1.31 & 0.02 & 0.19 & 0.98 & 0.73 \\
\hline TAG (mmol/l) & 1.43 & 1.41 & 1.45 & 1.44 & 0.07 & 0.95 & 0.19 & 0.19 \\
\hline \multicolumn{9}{|c|}{ Changes in cholesterol and bile acid metabolism } \\
\hline AUC $-{ }^{13} \mathrm{C}$ enrichment & 539.75 & 542.08 & $546 \cdot 41$ & 588.38 & $29 \cdot 80$ & 0.25 & 0.87 & 0.084 \\
\hline FSR for cholesterol (\%) & 8.37 & $9 \cdot 25$ & 7.54 & 7.80 & 0.76 & 0.14 & 0.63 & 0.23 \\
\hline $7 a-\mathrm{HC}(\mathrm{ng} / \mathrm{ml})$ & $11.05^{\mathrm{a}}$ & $12 \cdot 89^{\mathrm{a}, \mathrm{b}}$ & $11 \cdot 97^{\mathrm{a}, \mathrm{b}}$ & $14.00^{\mathrm{b}}$ & $1 \cdot 15$ & 0.049 & 0.31 & 0.26 \\
\hline
\end{tabular}

WR, wheat and rice; LMW, low-molecular weight; HMW, high-molecular weight.

a,b LSM in the same row with unlike superscript letters are significantly different among treatments (Fisher's least significant difference test for multiple comparison, $P<0.05$ ). 
Table 3. Changes in serum lipids, ${ }^{13} \mathrm{C}$-labelled cholesterol enrichment in erythrocytes, fractional synthesis rate (FSR) for cholesterol and serum $7 a$-hydroxy-4-cholesten-3-one $(7 a-\mathrm{HC})$ in response to $\beta$-glucan intervention for 5 weeks in three genotype groups of cholesterol $7 a$ hydroxylase SNP rs3808607

(Least squares means (LSM) with their standard errors)

\begin{tabular}{|c|c|c|c|c|c|c|}
\hline & \multicolumn{4}{|c|}{ Diet } & \multirow[b]{2}{*}{ SEM } & \multirow[b]{2}{*}{$P$} \\
\hline & WR control & $3 \mathrm{~g} \mathrm{LMW}$ & $5 \mathrm{~g} \mathrm{LMW}$ & $3 \mathrm{~g} \mathrm{HMW}$ & & \\
\hline \multicolumn{7}{|c|}{ Total cholesterol $(\mathrm{mmol} / \mathrm{l})$} \\
\hline $\mathrm{T} / \mathrm{T}(n 11)$ & $5 \cdot 40^{\mathrm{a}}$ & $5 \cdot 47^{a, b}$ & $5.66^{\mathrm{b}}$ & $5.59^{\mathrm{a}, \mathrm{b}}$ & 0.22 & 0.11 \\
\hline $\mathrm{G} / \mathrm{T}(n 11)$ & $5.53^{\mathrm{a}}$ & $5.44^{\mathrm{a}}$ & $5.52^{\mathrm{a}}$ & $5 \cdot 16^{\mathrm{b}}$ & 0.14 & 0.0093 \\
\hline $\mathrm{G} / \mathrm{G}(n 8)$ & $5.56^{\mathrm{a}}$ & $5 \cdot 43^{a, b}$ & $5.52^{a, b}$ & $5 \cdot 24^{\mathrm{b}}$ & 0.20 & 0.036 \\
\hline \multicolumn{7}{|c|}{ LDL-cholesterol $(\mathrm{mmol} / \mathrm{l})$} \\
\hline $\mathrm{T} / \mathrm{T}(n 11)$ & 3.32 & 3.22 & 3.33 & 3.40 & 0.085 & 0.39 \\
\hline $\mathrm{G} / \mathrm{T}(n 11)$ & 3.59 & 3.47 & 3.42 & 3.27 & 0.13 & 0.25 \\
\hline $\mathrm{G} / \mathrm{G}(n 8)$ & 3.55 & 3.49 & 3.58 & 3.32 & 0.17 & 0.0033 \\
\hline \multicolumn{7}{|c|}{ HDL-cholesterol $(\mathrm{mmol} / \mathrm{l})$} \\
\hline $\mathrm{T} / \mathrm{T}(n 11)$ & $1.59^{\mathrm{a}}$ & $1.47^{\mathrm{b}}$ & $1.51^{a, b}$ & $1.55^{\mathrm{a}, \mathrm{b}}$ & 0.030 & 0.053 \\
\hline $\mathrm{G} / \mathrm{T}(n 11)$ & 1.31 & 1.21 & 1.26 & 1.22 & 0.037 & 0.18 \\
\hline $\mathrm{G} / \mathrm{G}(n 8)$ & 1.33 & 1.36 & 1.32 & 1.31 & 0.031 & 0.72 \\
\hline \multicolumn{7}{|l|}{ TAG $(\mathrm{mmol} / \mathrm{l})$} \\
\hline $\mathrm{T} / \mathrm{T}(n 11)$ & 1.28 & 1.57 & 1.60 & 1.64 & 0.13 & 0.066 \\
\hline $\mathrm{G} / \mathrm{T}(n 11)$ & 1.78 & 1.66 & 1.80 & 1.54 & 0.12 & 0.39 \\
\hline $\mathrm{G} / \mathrm{G}(n 8)$ & 1.45 & 1.32 & 1.31 & 1.34 & 0.11 & 0.77 \\
\hline \multicolumn{7}{|c|}{ AUC $-{ }^{13} \mathrm{C}$ enrichment in erythrocytes } \\
\hline $\mathrm{T} / \mathrm{T}(n 11)$ & 581.65 & 541.96 & 558.85 & 556.92 & 47.02 & 0.50 \\
\hline $\mathrm{G} / \mathrm{T}(n 11)$ & 493.25 & 563.53 & 554.82 & 533.48 & 40.09 & 0.39 \\
\hline $\mathrm{G} / \mathrm{G}(n 8)$ & 544.57 & 519.55 & 523.8 & 673.75 & $72 \cdot 12$ & 0.070 \\
\hline \multicolumn{7}{|c|}{ FSR for cholesterol (\%) } \\
\hline $\mathrm{T} / \mathrm{T}(n 11)$ & 6.08 & 7.96 & 8.63 & $9 \cdot 18$ & $1 \cdot 10$ & 0.12 \\
\hline $\mathrm{G} / \mathrm{T}(n 11)$ & 8.90 & 8.70 & 7.92 & $10 \cdot 40$ & $1 \cdot 21$ & 0.24 \\
\hline $\mathrm{G} / \mathrm{G}(n 8)$ & 8.23 & $6 \cdot 13$ & 8.54 & 8.07 & $1 \cdot 78$ & 0.49 \\
\hline \multicolumn{7}{|c|}{$7 a-\mathrm{HC}(\mathrm{ng} / \mathrm{ml})$} \\
\hline $\mathrm{T} / \mathrm{T}(n 11)$ & $10 \cdot 23$ & 12.88 & 9.77 & 11.75 & 1.26 & 0.27 \\
\hline $\mathrm{G} / \mathrm{T}(n 11)$ & $16 \cdot 60$ & 15.49 & 15.85 & $18 \cdot 62$ & 1.26 & 0.57 \\
\hline $\mathrm{G} / \mathrm{G}(n 8)$ & $8 \cdot 13^{a}$ & $10 \cdot 00^{a, b}$ & $10 \cdot 96^{a, b}$ & $12 \cdot 59^{b}$ & 1.32 & 0.033 \\
\hline
\end{tabular}

WR, wheat and rice; LMW, low-molecular weight; HMW, high-molecular weight.

a,b LSM in the same row with unlike superscript letters are significantly different among treatments (Fisher's least significant difference test for multiple comparison, $P<0.05$ ).

strength is weak $(P=0 \cdot 0008$, Spearman's $\rho=-0 \cdot 30)$. Serum $7 \alpha$-HC concentrations were not related to either AUC of ${ }^{13} \mathrm{C}$ enrichment in erythrocytes or FSR for cholesterol.

\section{Discussion}

Consistent with the previous findings that high-viscosity $\beta$-glucan with HMW is effective in reducing circulating cholesterol levels ${ }^{(2)}$, we found that consumption of $3 \mathrm{~g} / \mathrm{d}$ HMW $\beta$-glucan resulted in higher serum $7 \alpha$-HC levels compared with the control, but not either of the LMW $\beta$-glucan diets. However, cholesterol absorption or cholesterol synthesis was not changed by any of the $\beta$-glucan diets. These results indicate the importance of the physiochemical characteristics of $\beta$-glucan in its cholesterol-lowering action and suggest that increasing bile acid synthesis rather than inhibition of cholesterol synthesis or absorption is the mechanism responsible for the cholesterollowering effect of $\beta$-glucan.

Inhibition of cholesterol absorption has been speculated widely as one of the mechanisms responsible for the cholesterollowering effect of $\beta$-glucan ${ }^{(13)}$. Hypothetically, with the viscous property, $\beta$-glucan might impact lipid absorption by altering the luminal environment such as slowing the transit time and
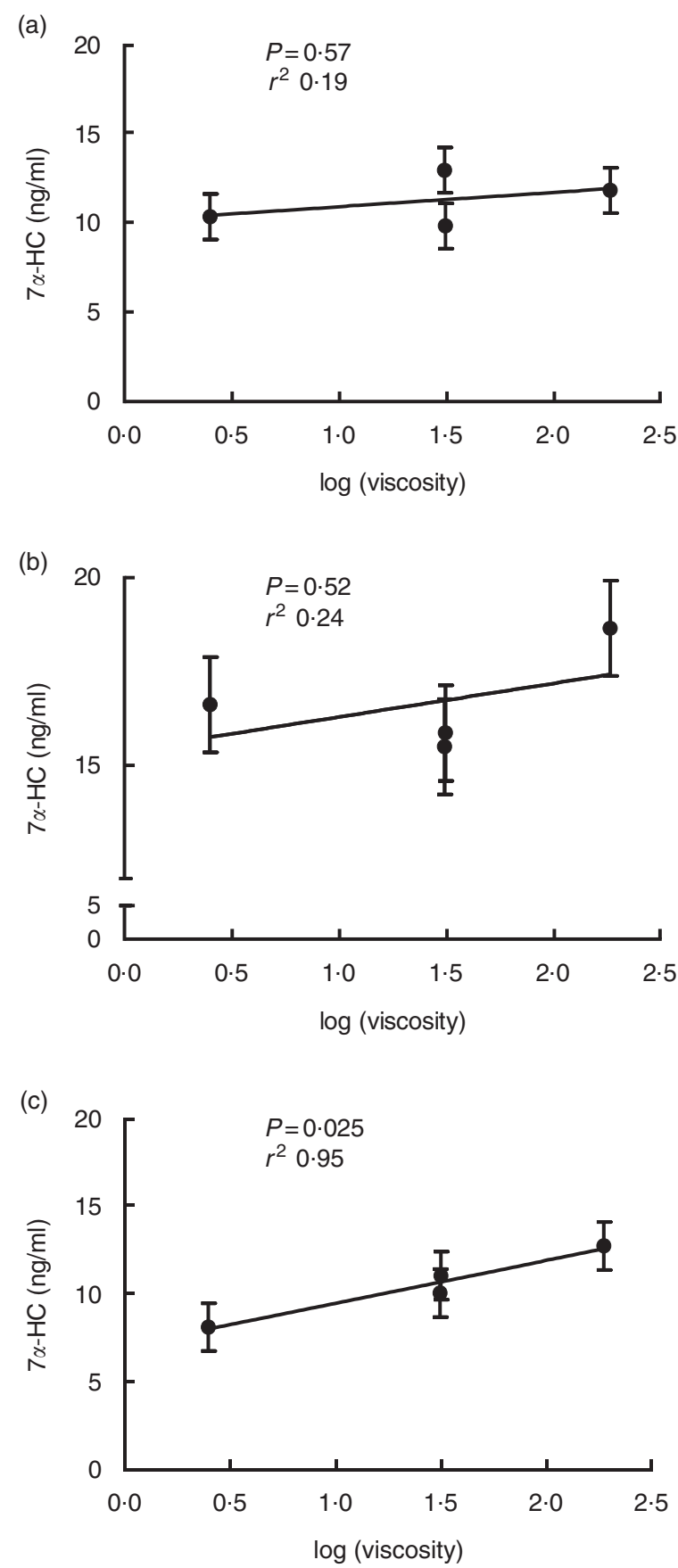

Fig. 1. Linear relationship between $7 a$-hydroxy-4-cholesten-3-one $(7 a-\mathrm{HC})$ concentration and log (viscosity) for the three genotype carriers of cholesterol 7a hydroxylase (CYP7A1) SNP rs3808607. (a) T/T carriers; (b) G/T carriers; (c) $G / G$ carriers. Values are least squares means with their standard errors for the four treatments following the order of wheat and rice control, $3 \mathrm{~g}$ low-molecular weight (LMW), $5 \mathrm{~g} \mathrm{LMW}$ and $3 \mathrm{~g}$ high-molecular weight from left to right.

increasing the thickness of UWL, or affecting activities of digestive enzymes and the formation of micelles ${ }^{(4,26)}$. Naumann et al. reported that sitosterol as a cholesterol absorption marker was decreased in a fruit drink containing $\beta$-glucan ${ }^{(27)}$; however, in an ileostomy study, Lia et ll $^{(28)}$ found no changes in the absorption of dietary cholesterol after an oat bran meal containing $\beta$-glucan using a radioisotope method with $\left[\beta-4-{ }^{14} \mathrm{C}\right]$-sitosterol and 
Table 4. Non-parametric correlation between cholesterol absorption, synthesis and bile acid synthesis

\begin{tabular}{lccl}
\hline Variables & By variable & Spearman's $\rho$ & \multicolumn{1}{c}{$P$} \\
\hline FSR & AUC & -0.30 & 0.0008 \\
& $7 a-\mathrm{HC}$ & 0.15 & 0.13 \\
AUC & FSR & -0.30 & 0.0008 \\
& $7 a-\mathrm{HC}$ & -0.074 & 0.44 \\
$7 a-\mathrm{HC}$ & FSR & 0.15 & 0.13 \\
& AUC & -0.074 & 0.44 \\
\hline
\end{tabular}

Spearman's $\rho$, Spearman's correlation coefficient; FSR, fractional rate of synthesis for cholesterol; 7a-HC, 7a-hydroxy-4-cholesten-3-one.

$\left[1 \alpha, 2 \alpha-n^{3} \mathrm{H}\right]$-cholesterol as tracers. This discrepancy may be due to the different methodologies used for measuring cholesterol absorption. As an inhibitor of intestinal cholesterol uptake, the use of sitosterol may lead to an underestimation of the actual capacity of absorption ${ }^{(29)}$. In agreement with Lia et al.'s finding, our study using a single isotope method showed that cholesterol absorption after consuming a $\beta$-glucan diet did not differ from the control diet $(P=0 \cdot 25)$. Therefore, our results provide more evidence suggesting that the cholesterol-lowering effect of $\beta$-glucan is not mediated through the inhibition of cholesterol absorption but through alternative mechanisms.

The ${ }^{2} \mathrm{H}$ incorporation method utilised in this study is a reliable means to assess cholesterogenesis ${ }^{(30)}$. Ellegard et al. ${ }^{(31)}$ reported in ileostomy patients that within $24 \mathrm{~h}$ consumption of native $\beta$-glucan increased bile acid excretion and also increased serum lathosterol concentration, a marker for cholesterol synthesis. Cholesterol homoeostasis is regulated by both cholesterol input and output. The loss of bile acid in excretion and demand for cholesterol to replenish the bile acid pool can possibly up-regulate the synthesis of cholesterol ${ }^{(13)}$. However, in our study, changes in cholesterol FSR did not reach statistical significance $(P=0 \cdot 14)$. Despite the discrepancy in increasing and not changing cholesterol synthesis, results of both Ellegard et al.'s and our present study do not support the hypothesis that consumption of $\beta$-glucan inhibits the cholesterol synthesis.

Our results demonstrated that consumption of HMW $\beta$-glucan is able to increase bile acid synthesis. Moreover, our data also revealed that the high viscosity resulting from HMW of $\beta$-glucan is the factor that drove this mechanism: serum $7 \alpha$-HC concentrations showed a linear relationship with the viscosity of the treatment diets (Fig. 1). After ingestion, high-viscosity $\beta$-glucan enters the lumen of the small intestine, where it may act similarly as a bile acid sequestrating agent to interact with bile acids and lead to bile acid being entrapped instead of being reabsorbed. The expected consequences of these actions would increase faecal bile acid loss and enhance bile acid synthesis from cholesterol to replenish the bile acid pool ${ }^{(13)}$. The interruption of enterohepatic circulation of bile acid caused by $\beta$-glucan has been reported in ileostomy patients ${ }^{(28,31-34)}$. In a short-term interventional cross-over study, nine participants with conventional ileostomies received a diet containing either native or hydrolysed $\beta$-glucan $(11.6 \mathrm{~g}$ ), each for $3 \mathrm{~d}$. The native $\beta$-glucan consumption resulted in $40 \%$ more ileal bile acid excretion compared with consuming the hydrolysed $\beta$-glucan diet. Moreover, native $\beta$-glucan in this study also increased serum $7 \alpha$-HC levels by $57 \%$ within 24 h of consumption ${ }^{(31)}$. A study from Marlett et al. investigated whether oat $\beta$-glucan lowers cholesterol levels by decreasing bile acid and fat absorption and increasing bile acid synthesis in nine normolipidaemic men. Participants consumed a low-fibre diet for $28 \mathrm{~d}$ followed by an oat bran diet containing $5.4 \mathrm{~g}$ of soluble $\beta$-glucan for another $28 \mathrm{~d}$ without an interval ${ }^{(14)}$. The oat bran diet resulted in increased synthesis and fractional turnover rates of two primary bile acid cholic acid and chenodeoxycholic acid, along with decreased serum cholesterol levels compared with a low-fibre diet without $\beta$-glucan ${ }^{(14)}$. These previous studies observed bile acid metabolism being interrupted by $\beta$-glucan but possess limitations such as small sample size $(n<10)$. Moreover, the ileostomy studies used short intervention periods of just a few days. Marlett et al. had a longer term for intervention but lacked a washout period. Therefore, results from the present study using thirty healthy participants with a controlled, randomised cross-over design provide stronger evidence to support that $\beta$-glucan reduces circulating cholesterol concentration through increasing bile acid synthesis.

The cholesterol-lowering effect of $\beta$-glucan was associated with the genetic variation of CYP7A1 rs3808607. Specifically, individuals carrying SNP rs3808607-G allele CYP7A1 were more responsive to HMW $\beta$-glucan in lowering LDL-cholesterol levels. In the present study, the participants were sub-grouped based on genotypes of CYP7A1 SNP rs3808607, and we found that individuals carrying homozygote for $G$ allele $(G / G)$ showed significant response to $3 \mathrm{~g} / \mathrm{d}$ HMW $\beta$-glucan in increasing $7 \alpha$-HC concentrations compared with control, but not for participants who carry $\mathrm{T} / \mathrm{T}$ and $\mathrm{G} / \mathrm{T}$ genotype of CYP7A1 SNP rs3808607. This result reveals the important role of CYP7A1 in the bile acid interruption mechanism and the influence of the genetic variation in this action. As reported previously, G-allele mediates greater gene expression than homozygote $\mathrm{T}$ based on increased transcriptional activity, which was suggested to increase bile acid synthesis in the liver as CYP7A1 is the key enzyme in the classical pathway ${ }^{(18)}$. These results confirm that rs3808607-G allele carriers are more responsive to elimination of bile acids from the enterohepatic circulation caused by $\beta$-glucan ${ }^{(14,28,31-33)}$. As a consequence, under the stimulation of 3 g HMW $\beta$-glucan that 'bound' or 'entrapped' the greatest amount of bile acid, $\mathrm{G} / \mathrm{G}$ carriers responded more to the 'elimination signal' given by the decreased level of primary bile acid in the liver, to produce more bile acid to restore the bile acid pool.

A negative correlation between AUC of ${ }^{13} \mathrm{C}$ enrichment and FSR was observed, which agrees with the theory that when more free cholesterol enters the liver from the diet, synthesis of cholesterol will be suppressed, and vice versa. Yet, neither of these pathways was influenced by $\beta$-glucan intervention. The concentration of $7 \alpha$-HC increased by $3 \mathrm{~g} / \mathrm{d}$ HMW $\beta$-glucan but was corrected with neither cholesterol absorption nor cholesterol synthesis. Accordingly, it is reasonable to speculate that interrupting bile acid enterohepatic circulation might be the sole mechanism for the cholesterol-lowering effect of $\beta$-glucan. This notion is further supported by the observation that $\log$ (viscosity) of $\beta$-glucan has a linear relationship with $7 \alpha$-HC levels but not with cholesterol absorption or synthesis parameters. 
This study is an extension of a previous published study with serum cholesterol changes as the primary outcome ${ }^{(2)}$. It should be noted that sample size of this study was not determined for detecting changes in cholesterol and bile acid metabolism following $\beta$-glucan consumption or the interaction between genetic variation of CYP7A1 SNP rs3808607 and $\beta$-glucan intervention. Although the distribution of genoptype of $C Y P 7 A 1$ SNP rs3808607 among the participants in this study is similar to the minor genotype frequency reported in the general population $^{(25)}$, we suggest a future study with appropriate sample size to confirm our current findings.

Overall, results in the current study showed that consumption of $3 \mathrm{~g}$ HMW $\beta$-glucan increased serum $7 \alpha$-HC but did not change the AUC of ${ }^{13} \mathrm{C}$-cholesterol enrichment in erythrocytes and FSR for cholesterol. Secondarily, aligning with our previous findings, homozygous rs3808607-G allele carriers resulted in greater responses in lowering cholesterol levels and a higher level of bile acid synthesis after ingesting $3 \mathrm{~g} \mathrm{HMW} \beta$-glucan. In conclusion, our results suggest that interrupting enterohepatic circulation of bile acids rather than inhibiting cholesterol absorption and synthesis might be the mechanism responsible for the cholesterol-lowering effect of $\beta$-glucan; the different responsiveness of individuals to the cholesterol-lowering effect of $\beta$-glucan might be attributed to the different levels of bile acid synthesis of the three genotypes, G/G, G/T and T/T following $\beta$-glucan consumption.

\section{Acknowledgements}

The authors thank Tracy Exley and Camille Rhymer for their technical support as well as Parrheim Foods (Saskatoon, SK Canada) and barley breeder Brian Rossnagel from the University of Saskatchewan for providing the barley raw materials used in the treatments.

The research was funded by Agriculture and Agri-Food Canada's Growing Forward.

S. M. T. and N. P. A. designed the research; Y. W. and S. V. H. conducted the research; P. J. H. J. provided facilities, technical support and supervisions for stable isotope analysis; S. J. T. helped with the sample extractions and manuscript preparation; Y. W. analysed the data and performed the statistical analysis; Y. W. and N. P. A. wrote the paper. N. P. A. had primary responsibility for final content. All authors read and approved the final manuscript.

None of the authors has any conflicts of interest to declare.

\section{References}

1. Wolever TM, Tosh SM, Gibbs AL, et al. (2010) Physicochemical properties of oat beta-glucan influence its ability to reduce serum LDL cholesterol in humans: a randomized clinical trial. Am J Clin Nutr 92, 723-732.

2. Wang Y, Harding SV, Eck P, et al. (2016) High-molecularweight beta-glucan decreases serum cholesterol differentially based on the CYP7A1 rs3808607 polymorphism in mildly hypercholesterolemic adults. J Nutr 146, 720-727.

3. van der Velde AE, Vrins CL, van den Oever K, et al. (2007) Direct intestinal cholesterol secretion contributes significantly to total fecal neutral sterol excretion in mice. Gastroenterology 133, 967-975.
4. Eastwood MA \& Morris ER (1992) Physical properties of dietary fiber that influence physiological function: a model for polymers along the gastrointestinal tract. Am J Clin Nutr 55, 436-442.

5. Chassard C \& Lacroix C (2013) Carbohydrates and the human gut microbiota. Curr Opin Clin Nutr Metab Care 16, 453-460.

6. Cantarel BL, Lombard V \& Henrissat B (2012) Complex carbohydrate utilization by the healthy human microbiome. PLOS ONE 7, e28742.

7. Illman RJ \& Topping DL (1985) Effects of dietary oat bran on faecal steroid excretion, plasma volatile fatty acids and lipid synthesis in rats. Nutr Res 8, 839-846.

8. Bird AR, Jackson M, King RA, et al. (2004) A novel highamylose barley cultivar (Hordeum vulgare var. Himalaya 292) lowers plasma cholesterol and alters indices of large-bowel fermentation in pigs. Br J Nutr $\mathbf{9 2}, 607-615$.

9. Gunness P \& Gidley MJ (2010) Mechanisms underlying the cholesterol-lowering properties of soluble dietary fibre polysaccharides. Food Funct 1, 149-155.

10. Martinez-Augustin O \& Sanchez de Medina F (2008) Intestinal bile acid physiology and pathophysiology. World J Gastroenterol 14, 5630-5640.

11. Charlton-Menys V \& Durrington PN (2008) Human cholesterol metabolism and therapeutic molecules. Exp Physiol 93, 27-42.

12. Cohen DE (2008) Balancing cholesterol synthesis and absorption in the gastrointestinal tract. J Clin Lipidol 2, S1-S3.

13. Chen J \& Huang XF (2009) The effects of diets enriched in beta-glucans on blood lipoprotein concentrations. J Clin Lipidol 3, 154-158.

14. Marlett JA, Hosig KB, Vollendorf NW, et al. (1994) Mechanism of serum cholesterol reduction by oat bran. Hepatology $\mathbf{2 0}$, $1450-1457$

15. Zhang JX, Hallmans G, Andersson H, et al. (1992) Effect of oat bran on plasma cholesterol and bile acid excretion in nine subjects with ileostomies. Am J Clin Nutr 56, 99-105.

16. Sauter G, Berr F, Beuers U, et al. (1996) Serum concentrations of 7alpha-hydroxy-4-cholesten-3-one reflect bile acid synthesis in humans. Hepatology 24, 123-126.

17. Axelson M, Bjorkhem I, Reihner E, et al. (1991) The plasma level of 7 alpha-hydroxy-4-cholesten-3-one reflects the activity of hepatic cholesterol 7 alpha-hydroxylase in man. FEBS Lett 284, 216-218.

18. De Castro-Oros I, Pampin S, Cofan M, et al. (2011) Promoter variant $-204 \mathrm{~A}>\mathrm{C}$ of the cholesterol 7alpha-hydroxylase gene: association with response to plant sterols in humans and increased transcriptional activity in transfected HepG2 cells. Clin Nutr 30, 239-246.

19. Friedewald WT, Levy RI \& Fredrickson DS (1972) Estimation of the concentration of low-density lipoprotein cholesterol in plasma, without use of the preparative ultracentrifuge. Clin Chem 18, 499-502.

20. Kassis AN \& Jones PJ (2008) Changes in cholesterol kinetics following sugar cane policosanol supplementation: a randomized control trial. Lipids Health Dis 7, 17.

21. Rideout TC, Chan YM, Harding SV, et al. (2009) Low and moderate-fat plant sterol fortified soymilk in modulation of plasma lipids and cholesterol kinetics in subjects with normal to high cholesterol concentrations: report on two randomized crossover studies. Lipids Health Dis $\mathbf{8}, 45$.

22. Folch J, Lees M \& Sloane Stanley GH (1957) A simple method for the isolation and purification of total lipides from animal tissues. J Biol Chem 226, 497-509.

23. Jones PJ, Leitch CA, Li ZC, et al. (1993) Human cholesterol synthesis measurement using deuterated water. Theoretical and procedural considerations. Arterioscler Thromb 13, 247-253.

24. Burkard I, von Eckardstein A \& Rentsch KM (2005) Differentiated quantification of human bile acids in serum by high-performance 
liquid chromatography-tandem mass spectrometry. J Chromatogr B Analyt Technol Biomed Life Sci 826, 147-159.

25. Flicek P, Ahmed I, Amode MR, et al. (2013) Ensembl 2013. Nucleic Acids Res 41, D48-D55.

26. Rideout TC, Harding SV, Jones PJ, et al. (2008) Guar gum and similar soluble fibers in the regulation of cholesterol metabolism: current understandings and future research priorities. Vasc Health Risk Manag 4, 1023-1033.

27. Naumann E, van Rees AB, Onning G, et al. (2006) Beta-glucan incorporated into a fruit drink effectively lowers serum LDLcholesterol concentrations. Am J Clin Nutr 83, 601-605.

28. Lia A, Andersson H, Mekki N, et al. (1997) Postprandial lipemia in relation to sterol and fat excretion in ileostomy subjects given oat-bran and wheat test meals. Am I Clin Nutr 66, 357-365.

29. Mackay D \& Jones PJ (2011) Evaluation of methods for the determination of cholesterol absorption and synthesis in humans. Atherosclerosis 218, 253-262.
30. Jones PJ, Ausman LM, Croll DH, et al. (1998) Validation of deuterium incorporation against sterol balance for measurement of human cholesterol biosynthesis. J Lipid Res 39, $1111-1117$

31. Ellegard L \& Andersson H (2007) Oat bran rapidly increases bile acid excretion and bile acid synthesis: an ileostomy study. Eur J Clin Nutr 61, 938-945.

32. Zhang JXH, G, Andersson H, Bosaeus I, et al. (1992) Effect of oat bran on plasma cholesterol and bile acid excretion in nine subjects with ileostomies. Am J Clin Nutr 56, 99-105.

33. Andersson M, Ellegard L \& Andersson H (2002) Oat bran stimulates bile acid synthesis within $8 \mathrm{~h}$ as measured by 7 alphahydroxy-4-cholesten-3-one. Am J Clin Nutr 76, 1111-1116.

34. Lia A, Hallmans G, Sandberg AS, et al. (1995) Oat beta-glucan increases bile acid excretion and a fiber-rich barley fraction increases cholesterol excretion in ileostomy subjects. Am J Clin Nutr 62, 1245-1251. 